\title{
Performance of hotel investment in a multi-property commercial real estate portfolio: Analysis of results from 1982 to 2001
}

Received: 24 June 2003

\section{Gabriel A-Petersen}

MSc, is Director of Corporate Strategy for Westmont Hospitality Group, one of the world's largest privately held hotel real estate investors with a diversified portfolio of over 350 hotels worldwide. He studied economics and hotel management and has a Masters degree in real estate from the University of Reading, UK. He has specialised in finance and investment matters within the hotel business and the real estate industry. On the academic front the focus of his research has been in the financial and investment aspects of real estate as an asset class, multi-property real estate portfolio diversification and specific aspects of hotel real estate. He can be contacted on g.peterson@westmontuk.com.

\section{Arjun Singh}

$\mathrm{PhD}$, is an assistant professor in the School of Hospitality Business at Michigan State University. His research, which focuses on lodging operations and real estate finance, has been published in key academic and industry publications such as Cornell Hotel and Restaurant Administration Quarterly, International Journal of Hospitality Management, Travel and Tourism Analyst, Journal of Lending and Credit Risk Management, Briefings in Real Estate Finance, Bottomline and Lodging.

\section{Abstract}

This paper reviews the performance of five real estate subsectors (office, retail, industrial, apartment and hotel) covering a 20-year (historical) period in order to assess the impact the hotel subsector would have when constructing a multi-property investment portfolio. The research was built on the foundation of modern portfolio theory, and the data were analysed using several statistical and investment analysis tools such as correlation analysis, Sharpe ratio and a portfolio optimiser. The results suggest that hotels can play a valuable role in a multi-property commercial real estate portfolio. This might encourage the industry to develop adequate databases such that performance and investment statistics' benchmarks can be offered for investors, to thus position the hotel

A. J. Singh

School of Hospitality Business

Eli Broad College of Business

Michigan State University

242 Eppley Centre

East Lansing, $\mathrm{Ml}$ 48824, USA

Tel: +1 5173539211

Fax: +1 5174321170

E-mail: singharj@msu.edu subsector as a viable asset alongside the other real estate subsectors in a property investment portfolio.

\section{Keywords:}

correlation analysis, diversification, efficient frontier, hotel performance, modern portfolio theory, multi-property real estate portfolio, Sharpe ratio 
The context of an investment portfolio

\section{Lack of consistent and quantifiable data to measure returns}

\section{INTRODUCTION}

Real estate is different from other investment assets due to several factors. Real estate property is unique in its location, physical structure, tenant mix and availability (lot size). In addition, property is a very illiquid asset and lacks a central market for price determination.

The fact that the real estate market is composed of noninterchangeable, unique and illiquid assets (properties) means that it is probably less efficient than other markets like bonds or stocks markets. ${ }^{1}$ On the other hand, a less efficient property market may present opportunities for skilled investors to exploit and secure superior investment results.

In a seminal work on real estate investment, Firstenberg et al. asked investors to broaden their view of real estate investment from the traditional property-specific 'micro' analysis to a 'macro' view. ${ }^{2}$ The latter approach, they said, should analyse the role of a specific real estate investment in the context of an investment portfolio. While the application of modern portfolio theory (MPT) has been common practice for institutional investors as a means of diversification, risk reduction and optimising returns from a multisecurity portfolio, its use by real estate investors was non-existent prior to the 1980s. Commenting on this lacuna, Firstenberg et al. state '... there has been a complete neglect of such theory and techniques in the management of real estate portfolios and in their integration into institutional portfolios. This, in turn, has deprived managers of the modern tools that they now employ when considering other financial decisions. ${ }^{3}$

While portfolio theory and the analytical tools existed prior to the 1980s, a legitimate constraint persisted for real estate researchers: lack of consistent and quantifiable data to measure returns. Until the NCREIF (National Council of Real Estate Investment Fiduciaries) property index was created in 1982, no publicly available data were available on real estate returns. It was only after the development of this database and its accompanying time series of sector-specific returns that real estate researchers were able to conduct diversification, albeit rudimentary, studies.

Furthermore, in the initial years of the NCREIF index the available data were aggregated, and therefore of limited use. Nowadays, however, sufficient time series and property-specific data exist, spanning a 20 -year period and two complete economic cycles. ${ }^{4}$

\section{LITERATURE REVIEW}

Some of the early research which applied MPT to real estate was influenced by the passage of the Employee Retirement Income Security Act (ERISA) in 1974. The Act held investment managers to high standards in their asset allocation methods, using the 'prudent man' yardstick. This, coupled with available data from NCREIF, resulted in a stream of research looking at the diversification benefits of real estate in a multi-asset portfolio.

\section{Diversification benefits}




\section{Low correlation with stocks}

\section{Hotel real estate}

Using a sample of real estate investment trusts, Miles and $\mathrm{McCue}^{5}$ found that diversification by property produced higher risk-adjusted returns than regional diversification. Survey research conducted by $\mathrm{Webb}^{6}$ found that property type and geographic diversification are important criteria for institutional investors. Research conducted by Ibbotson and Siegel ${ }^{7}$ and Hartzell ${ }^{8}$ indicated that commercial real estate offers diversification benefits to institutional investors because of its low correlation with stocks. Hartzell et al. ${ }^{9}$ found that property type diversification was more effective than regional diversification. Finally, Grissom et al. ${ }^{10}$ showed that portfolios which were diversified on the combined basis of geographic and property type reduced unsystematic risk more than those which diversified simply on the basis of geographic or property type.

Myer and Webb ${ }^{11}$ reviewed ten-year NCREIF returns for office, retail, $\mathrm{R} \& \mathrm{D}$ and industrial and found low correlations between all property-type categories, with the exception of office and warehouse. Their research also identified optimal portfolio mixes, which differed based on the sub-period analysed. Using NCREIF data, Mueller and Laposa ${ }^{12}$ found that different real estate property types go through economic cycles based on supply and demand. By constructing efficient frontiers and using returns during different real estate and economic cycles, they concluded that property type returns vary based on the time period.

Despite the variety of real estate diversification and asset allocation studies, with very few exceptions they focused mainly on what can be considered the 'traditional' subsectors within the real estate industry (office, retail, industrial and apartment - the latter mainly in the USA). From a real estate investment perspective, one property subsector that has not been widely considered (nor researched) is hotel real estate. A very limited number of studies have analysed the role of hotels in a multi-property or multi-asset portfolio.

Firstenberg et al. ${ }^{13}$ conducted the earliest study, examining the role of hotels in a multi-asset real estate portfolio. Their study showed how modern portfolio analysis can be used to diversify optimally a real estate portfolio. By using NCREIF returns from 1978 to 1985 , they showed that efficient frontier portfolios with the highest risk-return combination included hotels and offices. Their study was constrained, however, due to the short time span and serious under-representation of hotels in the early years of the NCREIF dataset.

deRoos and Corgel ${ }^{14}$ conducted some preliminary analysis which compared total hotel returns to the NCREIF. This comparison used various proprietary hotel indexes such as the Hospitality Valuation Index (HVI), the Pannell Kerr Forster Index (PKF), the American Council of Life Insurance Companies (ACLI) and the Cornell Index. This elementary analysis used total (income and capital) hotel return data from each of these indexes from 1984 to 


\section{Non-systematic risk}

\section{Few benchmarks}

\section{Optimal portfolio}

1993 and compared it to the NCREIF index. They reported that the average hotel returns were higher than NCREIF returns and in general were more volatile.

Following this study, Corgel and deRoos ${ }^{15}$ compared returns of the newly created lodging property index (LPI) ${ }^{16}$ with NCREIF returns. While the short time span (1995-1996) and other data limitations made this comparison of limited value, it showed higher returns but also higher variability. By breaking down the total return into income and capital components, they found that similar to the NCREIF - lodging properties are less volatile in terms of income returns compared to capital returns.

A recent study correlated the returns of the LPI with stock, bond and NCREIF indexes. Quan et al. ${ }^{17}$ found that lodging properties provided significant diversification benefits when combined in a portfolio of small company stocks and commercial real estate. Due to data limitations and a short sample period (1995-2000), however, their results may not be representative over longer business horizons.

\section{SIGNIFICANCE OF THE STUDY}

The objective of diversifying an investment portfolio is to reduce non-systematic risk. A variety of factors contribute to nonsystematic risk in real estate investments: lease terms, operating and financial leverage, demand versus supply of space, tenant mix and location. These in turn are affected by business cycles, cost of capital, inflation and economic and demographic trends. ${ }^{18}$ Hotel real estate in the USA alone, for example, represents over US\$100bn of unsecuritised investment-grade properties. ${ }^{19}$ A sector of this size suggests that it should be included in a well-diversified portfolio and be present in the minds of institutional real estate investors. A lack of understanding of the hotel business and its high-risk profile, combined with the dearth of research on the diversification benefits of hotels in an investment portfolio, has resulted in their marginal role in multi-property investment portfolios. As a result, institutional investors and institutional fund advisers have had little guidance and few benchmarks to measure the role of hotel properties in a multi-property real estate portfolio. The overriding goal of portfolio management is enhancing return and managing risk through the development of an optimal portfolio, so that risk-adjusted returns are maximised. ${ }^{20}$ It is the contention of the authors that by studying the role of hotels in a multi-property investment portfolio, institutional investors can optimise portfolio returns and reduce the overall risk level of a real estate portfolio. The study may provide further impetus to include hotel real estate performance data in other real estate indexes.

\section{STUDY PURPOSE}

The main objective of this paper is to examine the investment performance of hotels in relationship to other real estate property 


\section{Diversification benefits}

classes, and investigate the diversification benefits of including hotel real estate assets in a multi-property real estate portfolio.

\section{DATA AND METHODOLOGY}

Detailed property performance databases exist in what can be catalogued as the more transparent and sophisticated real estate markets (namely the USA and the UK). These databases tend to cover and provide detailed performance information mainly on the 'traditional' property subsectors (office, retail and industrial, plus apartments in the US case), but give very little information when it comes to the hotel subsector.

It is relevant to note that the financial information needed to perform this study had to follow the same methodology of calculation that the indexes used for the traditional property sectors, and thus had to have, at least, the following characteristics:

- provide total returns (quarterly or semi-annual), which include income and capital growth

- cover a representative historical period, ie at least 15 to 20 years of ex-post data.

This study used the semi-annual, quarterly returns produced by the NCREIF from 1982 to 2001. The NCREIF index is an index of the quarterly total returns ${ }^{21}$ of the commercial real estate properties held for tax-exempt institutional investors by the members of the NCREIF. The database includes only investment-grade properties and uses pre-tax and unleveraged performance measures for calculating rates of return. Development projects are excluded from the sample, and the market value of properties is determined by appraisal methodology, which is consistently applied. ${ }^{22}$

For the purposes of this study, historical total return data from the NCREIF index have been analysed. The sample of properties during the 20-year period being analysed (1982-2001) consist of approximately 2,700 to 3,000 properties. Depending on the historical period or sub-period covered, of this total number of properties, on average, offices represent approximately 25 per cent of the sample, retail approximately 20 per cent, industrial approximately 30-35 per cent, apartments approximately 15-20 per cent and hotels approximately $1-2$ per cent. ${ }^{23}$

The number of hotel properties in the sample, on average, thus tends to be significantly smaller than the number of properties in each of the other subsectors. This ratio is wider when analysing historical data beyond 15 years. When the hotel index was incorporated (early 1980s) the hotel property sample was very small and most probably does not reflect a true picture in terms of the diversification potential of the subsector in those years.

The data analysis was performed using Microsoft Excel statistical and financial functions. The efficient frontier for the study was developed using a portfolio optimiser in Microsoft Excel. $^{24}$ 


\section{ANALYSIS OF RESULTS}

The analysis of results is presented and discussed sequentially by first examining the trend in long-term returns of individual real estate asset classes (including the hotel subsector) in comparison to inflation and the gross domestic product (GDP). Summarising the long-term risk, return and adjusted return performances of individual real estate asset classes follows this. The returns of lodging properties are correlated with returns from other real estate asset classes to determine potential diversification benefits. Using the underlying, risk, return and correlation data, an efficient frontier of optimal portfolios is constructed, with and without hotels. Finally, illustrative (simulated) portfolios are built with different hotel allocation percentages to measure the impact on portfolio performance.

\section{Comparative performance of commercial real estate property sectors, 1982-2001}

\section{Long-term view}

\section{District cycles}

Analysing the performance of commercial real estate from 1982 to 2001 represents a long-term view of the industry. During this 20year period, commercial real estate evidenced two distinct cycles of supply growth and contraction. While various events have a common effect on the overall performance of all commercial property sectors, the results vary as each property type has a 'unique effect'. This is a result of specific events that affected the property sector (such as hotels) and the inherent dynamics of the businesses operating within the sector.

Figure 1 reviews the comparative trend in semi-annual returns of the five commercial real estate sectors: office, retail, industrial,

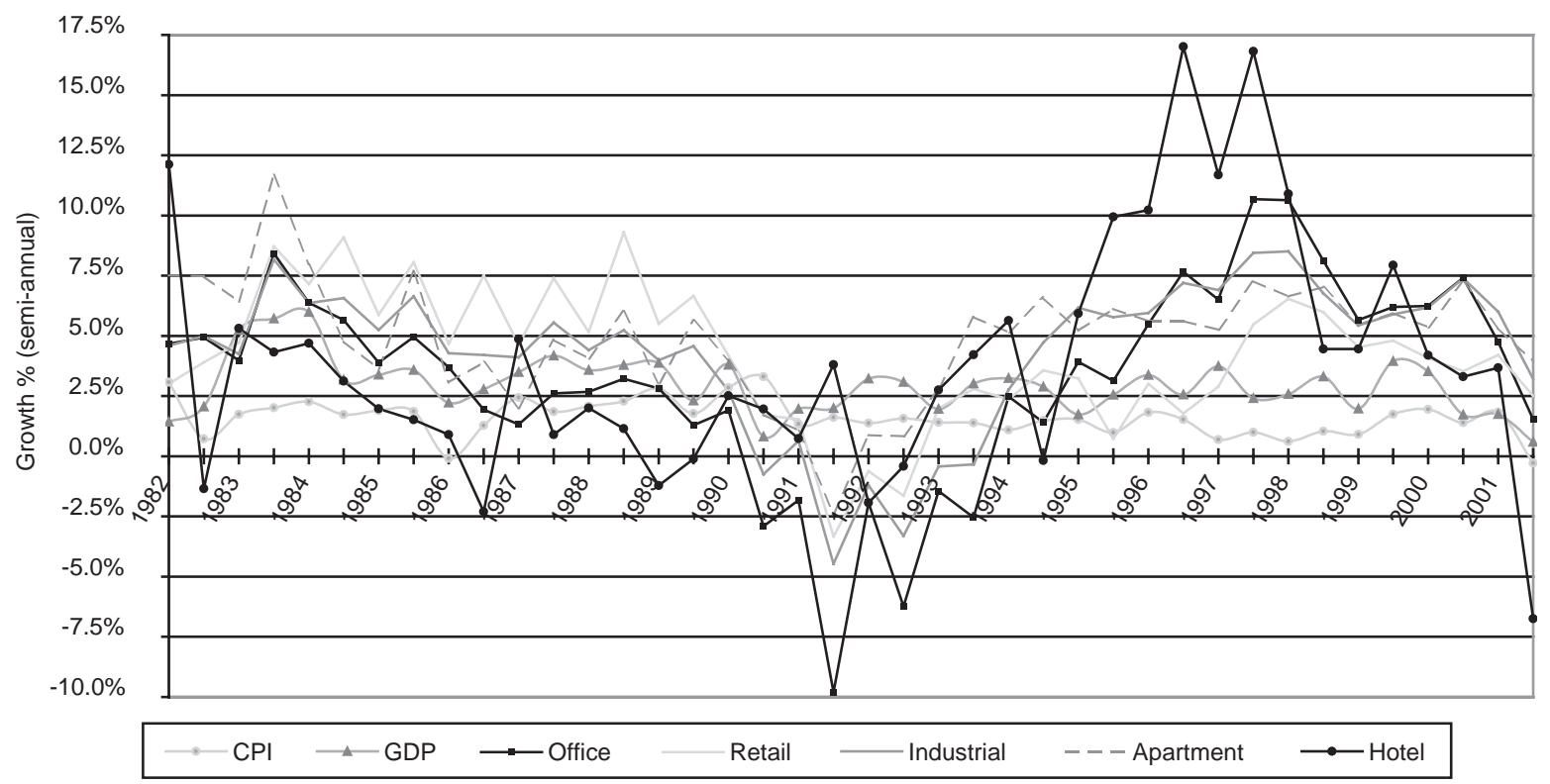

Figure 1: Growth trend in commercial property sectors (1982-2001) 
Specific factors unique to hotel real estate

\section{Oversupply}

Table I: Summary of multi-property type risk and return (1982-2001)

\begin{tabular}{lrcccc}
\hline & Office & Retail & Industrial & Apartment & Hotel \\
\hline Average semi-annual return (\%) & 3.24 & 4.18 & 4.33 & 4.95 & 4.02 \\
Risk (standard deviation) (\%) & 4.20 & 2.79 & 3.09 & 2.50 & 4.98 \\
Sharpe ratio & -0.10 & 0.19 & 0.22 & 0.52 & 0.07 \\
Annual return (geometric mean) (\%) & 6.09 & 8.04 & 8.33 & 9.59 & 7.57 \\
Average return (annualised) (\%) & 6.58 & 8.53 & 8.86 & 10.15 & 8.20 \\
\hline
\end{tabular}

apartment and hotel. The returns of each sector are compared to semi-annual changes in the GDP and consumer price index (CPI). Figures 2 and 3 track the trend in commercial property values during the study period in comparison to CPI and GDP. Several interesting features emerge from an analysis of these three figures. Table 1 summarises average returns, risk and the risk-adjusted return for the property sectors for the 20-year period studied.

First, as compared to the other property sectors it is clear that hotel returns have been more volatile over the period (Figure 1). The only other sector with similar volatility during the study period is the office sector. This is confirmed in Table 1, which shows that hotel and office sector returns had standard deviations of 4.98 and 4.20 per cent respectively.

As noted in Figure 1, sharp increases and drops in hotel returns are particularly noticeable in 1982-1983, 1986-1987, 1990-1992, 1993-1998, 1998-1999 and most recently after September 11th. This can be attributed to specific factors unique to hotel real estate, which positively or negatively impacted on returns. The 1980s started with a building boom because of four complementary factors: tax incentives for real estate investment, low interest rates, availability of capital and product segmentation. As a result, supply increased without a corresponding increase in demand, resulting in a sharp drop in returns in 1983 that continued until 1986. During the period from 1983 to 1987 , the annual growth of room supply was more than 4 per cent each year, and in 1987 it was over 7 per cent. Demand could not keep up with the frenzied pace with which new hotels were being added, and as a result hotel operators competed by slashing room rates. ${ }^{25}$

As the lodging industry entered the 1990s, it was severely affected by a national recession. The excess hotel building of the 1980s had resulted in a dramatic increase in numbers of hotel rooms. An overbuilt industry faced declining demand for rooms, due to a reduction of overall travel because of the Gulf War (1990-1991) and an economic recession. National occupancies bottomed out at 61.8 per cent in 1991. Due to the oversupply of rooms, hotels had to reduce room rates, which further affected profitability. The hotel industry suffered heavy losses during this period - net losses of US\$5.7bn in 1990 and US\$2.8bn in $1991 .^{26}$

The lodging returns started to show an upward trend in 1994 and continued to improve until 1998, as a result of demand catching up 


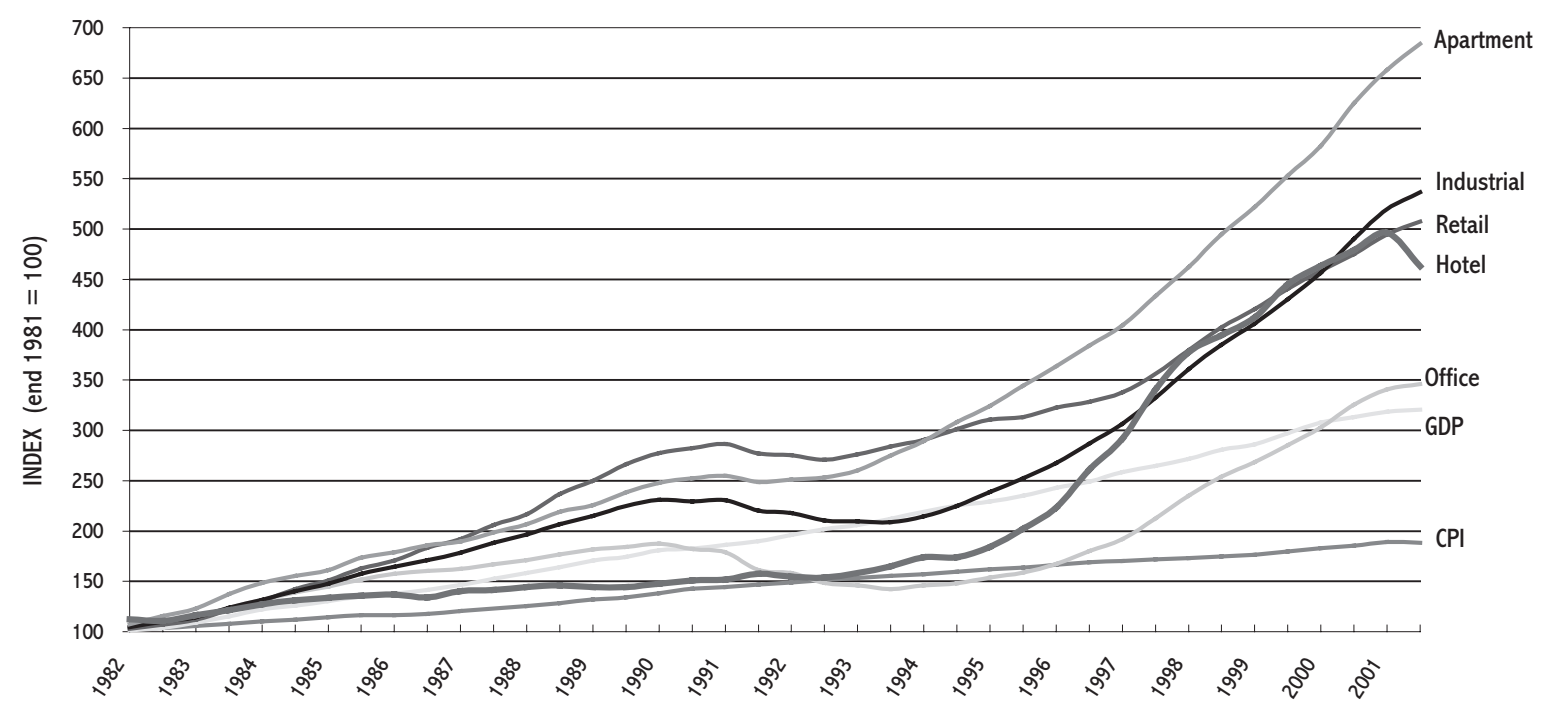

Figure 2: Cumulative value growth in commercial property sectors (1982-2001)

\section{Outperformed}

‘Event-driven’ decline with supply, unprofitable hotels exiting the market and hotel companies consolidating and operating more efficiently, combined with the ability of hotel companies to increase room rates and the steady improvement of economic growth (GDP). From 1995 to 1998, hotel returns significantly outperformed the other property sectors. Hotel returns started to show a decline after 1998, with the economic slowdown precipitated by the dot.com bust and culminating in a sharp 'event-driven' decline after the attacks of September 11th and the subsequent global war on terrorism.

\section{Growth in commercial property sector values, 1982-2001}

The supply-demand balance of hotel rooms during this period also affected the value of hotel real estate. As noted in Figures 2 and 3, from 1983 to 1987 the growth in hotel values was very gradual, with increases dipping below the growth in GDP in the late 1980s and marginally above inflation (CPI). During the early 1990s hotel values were at their lowest point, and growth in values was consistently below GDP and CPI until 1995. An over-leveraged and overbuilt hotel industry from 1990 to 1993 resulted in many hotel properties being taken back by the lender in a foreclosure or forming part of the real estate owned (REO) portfolio of savingsand-loan institutions which were acquired by the Resolution Trust Corporation (RTC) and sold at discounted prices.

The lodging industry values began to recover in 1993, a critical year for the industry. Occupancies and room rates increased and the industry was once again profitable. This was a combined result of supply-demand reaching equilibrium, a reduction in debt service due to the sale or restructuring of most distressed hotels and tighter controls instituted by management companies. During this 


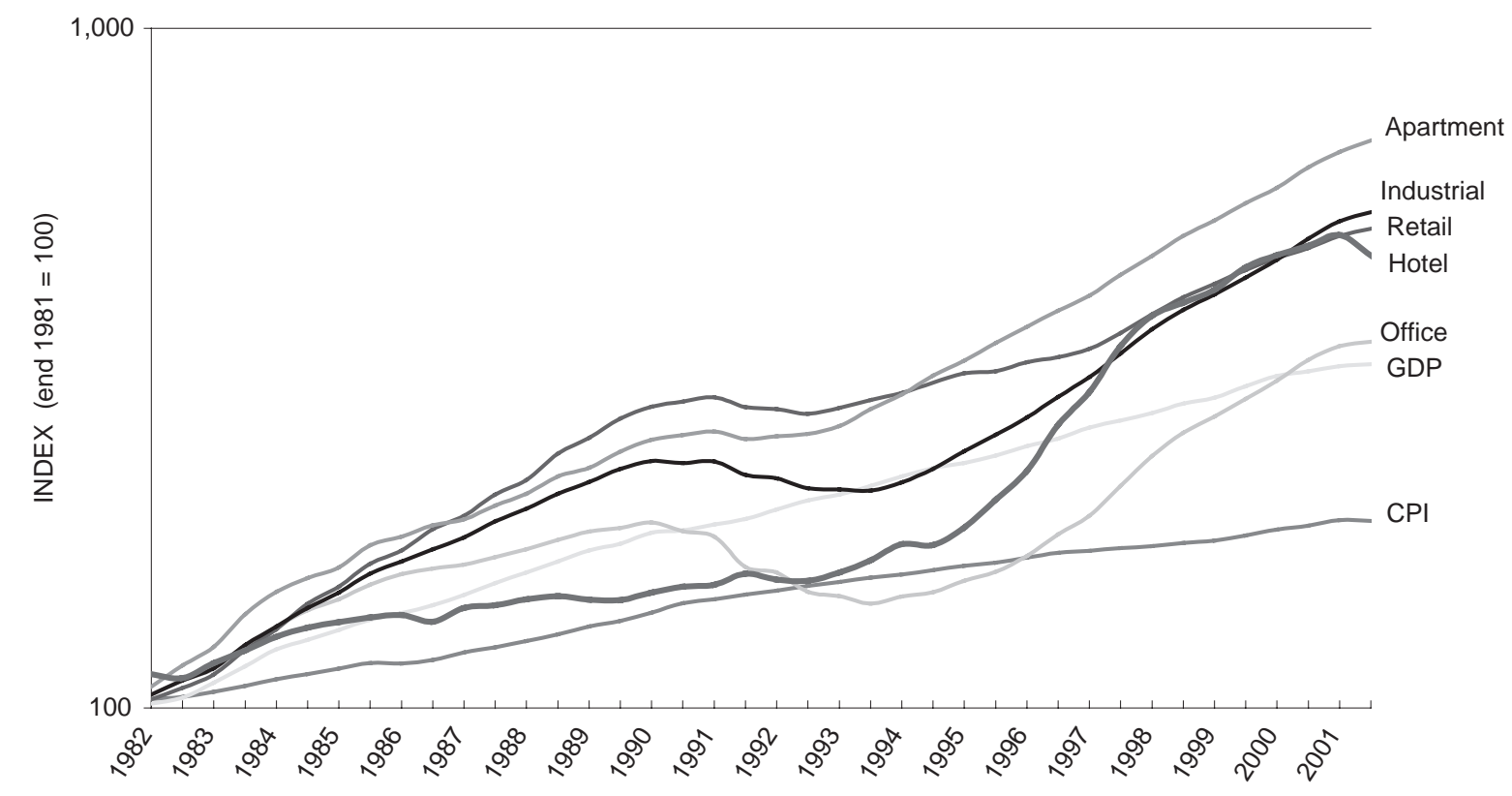

Figure 3: Logarithmic scale of cumulative value growth (1982-2001) (Logarithmic scale removes the exponential impact of compound growth over time)

\section{'Unique' industry effect} differences could be attributed to the 'unique' industry effect, which is the result of unique events impacting on a sector and the unique operational dynamics of the businesses operating within a property sector.

Because real estate prices (values) are a large component of the CPI, real estate values are unavoidably linked to inflation. As noted in Figures 2 and 3, in general, increases in real estate values exceeded inflation rates for the study period (1982-2001), with this divergence being most prominent during recovery from 1993 to 2001. In particular, the hotel real estate price appreciation showed great divergence from CPI during the recovery period from 1995 to 2001.

As noted in Figures 2 and 3, the observed evidence of growth in that real estate is an effective inflation hedge. Despite reduction in surpassed the office sector, GDP and CPI. While the growth in value was still below the apartment sector, it matched and at times exceeded industrial and retail property sectors.

Two other factors are notable from an analysis of the comparative growth in values in Figures 2 and 3. While all property sectors were affected by the recession of the early 1990s, the office sector was most severely affected, followed by hotels. Conversely, when recovery came in 1993, all property sectors showed increases in value, with the hotel sector showing the most dramatic increase (as noted by the inclination of the trend line). These observed real estate values compared to inflation verifies the long-held notion 


\section{Most effective inflation hedge compared to other property sectors}

\section{'Rental rate inertia'}

\author{
Diversification \\ potential
}

real estate values in the early 1990s, growth in values remained above CPI. The only exception was the office sector, which dipped below CPI between 1992 and 1995. In particular, hotels appear to be the most effective inflation hedge as compared to other property sectors, as they can adjust their 'leases' on a daily basis by altering their room rental rates to allow for increases in inflation. As such, they do not suffer from the 'rental rate inertia' which encumbers property sectors with long-term leases.

\section{Summary of performance (risk versus return) of property sectors, 1982-2001}

The previous analysis illustrated and examined the changes in return, volatility of these returns and appreciation in the value of real estate for a 20 -year period. Table 1 summarises and compares the total return, risk and risk-adjusted return for the hotel sector and the other property types included in the study. The apartment sector led all other sectors, with a total average return of 10.15 per cent. This was followed by the industrial, retail and hotel sectors, which recorded average annual returns of 8.86 per cent, 8.53 per cent and 8.20 per cent respectively. The office sector had the weakest performance, with average annual returns of 6.58 per cent.

The standard deviation, which is the measure of the riskiness of these returns, indicates that the hotel and office sectors had the most volatile returns, with standard deviations of 4.98 per cent and 4.20 per cent respectively. The other three property sectors had relatively low standard deviations ranging from 2.5 per cent for apartments to 3.09 for the industrial property sector.

The Sharpe ratio is a measure by which the total return of an asset (or portfolio) can be assessed in light of its accompanying risk. The Sharpe ratio therefore provides a measure of the 'riskadjusted return' of an asset by measuring how much excess return can be gained for each additional 'unit' of risk. This measure will allow detecting the overall benefits of each subsector within the real estate portfolio being analysed. ${ }^{27}$ The excess return compares the actual return to the risk-free rate, which in this case is the average ten-year US government bond yield corresponding to each of the periods being analysed.

The risk-adjusted returns were highest for the apartment sector (0.52), indicating the highest return for each unit of risk. Hotels were fourth in ranking, with a risk-adjusted ratio of 0.07 . The office sector had a negative return $(-0.10)$ on a risk-adjusted basis.

\section{Correlation of hotel returns with other property sectors, 1982-2001}

Correlating total returns between property types provides information about the diversification potential of a particular property sector in a multi-property portfolio. A low correlation with other assets implies the asset is a good diversifier. Combined with the individual risk and return profile of the property type, the 
Table 2: Cross-correlation matrix (Jan 1982 to Dec 2001)

\begin{tabular}{lrllllll}
\hline & CPI & GDP & Office & Retail & Industrial & Apartment & Hotel \\
\hline CPI & 1.00 & & & & & & \\
GDP & 0.28 & 1.00 & & & & & \\
Office & -0.15 & 0.25 & 1.00 & & & & \\
Retail & 0.14 & 0.45 & 0.63 & 1.00 & & & \\
Industrial & -0.12 & 0.26 & 0.96 & 0.70 & 1.00 & & \\
Apartment & -0.03 & 0.35 & 0.79 & 0.61 & 0.79 & 1.00 & 1.00 \\
Hotel & 0.04 & 0.07 & 0.50 & -0.06 & 0.43 & 0.34 & \\
\hline
\end{tabular}

\section{Optimal diversification mix}

\section{Mean-variance efficiency}

Risk/return analysis moves one step closer to devising an optimal diversification mix.

An analysis of Table 2 indicates that hotel returns have a low correlation with the apartment sector (0.34) and a negative correlation with the retail sector $(-0.06)$. Hotels show a relatively stronger correlation with the office $(0.50)$ and industrial $(0.43)$ subsectors. This suggests hotels can offer higher diversification benefits in portfolios with a heavier concentration of apartments and retail.

It is also important to note that the correlation between the traditional real estate property sectors (office, retail, industrial and apartment) is very high. These correlations range from a high of 0.96 between office and industrial sectors to the lowest correlation between retail and apartment sectors of 0.61. Thus, forming real estate portfolios with only the traditional sectors has low potential for portfolio risk reduction.

The ability for hotels to adjust room rates is reflected in the inflation protection offered by lodging properties (0.04). The longterm lease structure of other property sectors, such as office, industrial and apartment, results in a negative correlation with CPI.

\section{IDENTIFYING AN EFFICIENT FRONTIER OF INVESTMENT USING MPT}

Even though correlation analysis provides some information on an asset's potential for diversification, it does not consider the risk associated with including the asset in a portfolio. The areas not covered by the correlation analysis can be gained by applying MPT as an analytical tool. Although much criticised due to practical and theoretical difficulties, MPT remains the standard tool for investigating the relevance, and impact, of an asset in a multi-asset portfolio. $^{28}$

MPT uses the concept of mean-variance efficiency as a way to allocate capital among a portfolio of assets. Therefore, an 'optimal portfolio' is defined as one that maximises return for a given level of risk, or minimises risk for a given level of return. Inputs into the calculation of the 'optimal allocation' of, or within, a portfolio include estimates of expected return, standard deviation or variance (risk), and correlation of return for a set of assets. For this 


\section{MPT is an expectations theory}

\section{'Efficient frontiers of investment'}

Ideal asset allocation purpose, risk is defined as the variance (or standard deviation) of returns.

Following from the above, and given the nature of the data that will be used in this study, it is relevant to stress that MPT is an expectations theory and its proper application is meant to be done with some forecast of the expected performance of the assets within a portfolio. The inputs to generate the efficient frontier for this study used historical (ex-post) performance data related to risk, return and correlation of returns for each property type. ${ }^{29}$ When applying MPT using ex-post data, as it will be carried out in this study, it is done with the underlying assumption that, in effect, investors choosing the optimal portfolio(s) have perfect information on which to base their analysis at the beginning of each period.

Within the MPT framework, the diversification tool used to perform this paper's intended analysis is the construction of 'efficient frontiers of investment'. The efficient frontier is a way of showing, in a graphical form, the optimal allocation mentioned in the paragraph above. The frontier (line) in the graph will show the best possible risk-adjusted allocation of assets within a portfolio ranging from a minimum risk-low return (bottom left corner of the graph) to the maximum risk-high return (upper right-hand corner of the graph). Each point on the efficient frontier line corresponds to an ideal asset allocation (weight) to achieve a specific return and risk.

Figure 4 and Table 3 present the risk-return profile of the five major property types used for this study. The efficient frontier graphed in Figure 4 is based on the allocation percentages outlined in Table 3 and using 20-year ex-post NCREIF data (1982-2001). The portfolios along the efficient frontier would offer investors the highest level of return for a given level of risk and vice versa, and are therefore the dominant portfolios. The maximum risk-return portfolio consists of 100 per cent apartment real estate and would achieve an average semi-annual return of 4.95 per cent with a risk of 2.50 per cent. As the optimiser begins to add hotels and retail real estate assets, however, diversification benefits begin to accrue, and the highest risk-return portfolio allocations emerge and are graphed along the frontier. The portfolio with the minimum variance (bottom left on the frontier) has a 15 per cent allocation of hotels, 41 per cent apartments and 44 per cent retail. The risk of this portfolio is 2.25 per cent with an average semi-annual return of 4.47 per cent.

Due to the lower correlation between the three assets in the portfolio, the hotel subsector, if included in the portfolio, does contribute to a more optimally and diversified investment, particularly at the low-risk end of the efficient frontier. It is important to note that the low correlation between the three assets results in diversification benefits (risk reduction) at all allocation percentages along the illustrated efficient frontier in Figure 4, 


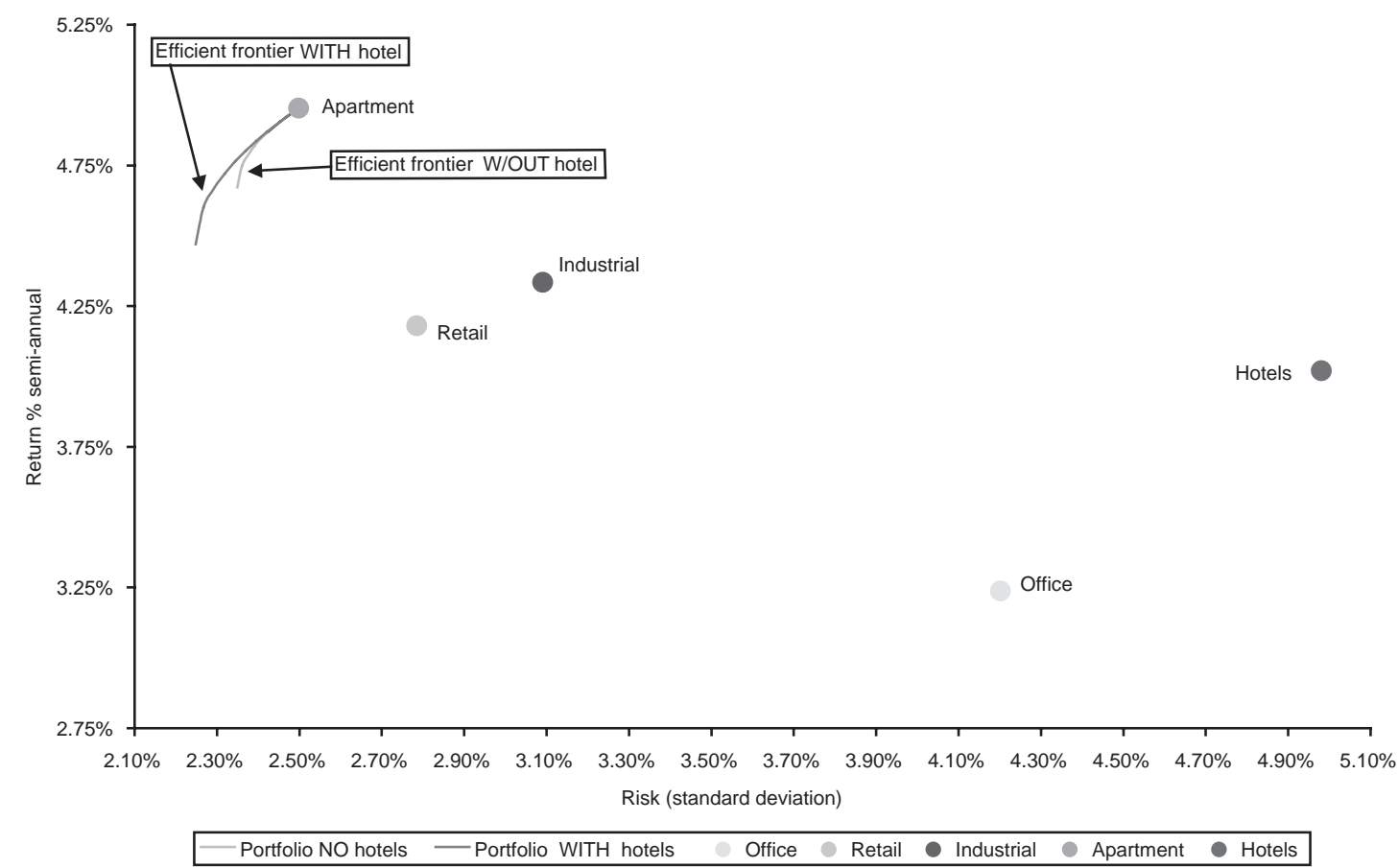

Figure 4: Efficient frontiers with and without hotel real estate (Jan 1982 to Dec 2001)

despite the fact that hotel returns are more volatile and therefore riskier.

An analysis of the frontier (Figure 4) and accompanying allocation table (Table 3 ) reveals some more insights. Investors and portfolio managers looking to create a portfolio with a higher riskreturn profile should weight it heavily with apartment real estate, and include a miniscule percentage of hotel real estate and a small amount of retail real estate. Those investors willing to accept a little less return and reduce commensurate risk will increase their retail allocation (12-18 per cent) and hotel allocation (3-5 per cent) and

Table 3: Allocation weights and risk/return range (jan 1982 to Dec 2001)

\begin{tabular}{|c|c|c|c|c|c|c|c|}
\hline Office \% & Retail \% & Industrial \% & Apartment \% & Hotel \% & & Risk \% & Return \% \\
\hline & & & 100 & & Maximum & 2.50 & 4.95 \\
\hline & 3 & & 97 & & return & 2.47 & 4.93 \\
\hline & 6 & & 93 & 1 & $\Delta$ & 2.45 & 4.90 \\
\hline & 9 & & 90 & 2 & & 2.42 & 4.87 \\
\hline & 12 & & 86 & 3 & & 2.40 & 4.84 \\
\hline & 15 & & 81 & 4 & & 2.37 & 4.80 \\
\hline & 18 & & 77 & 5 & & 2.34 & 4.77 \\
\hline & 22 & & 72 & 7 & & 2.32 & 4.72 \\
\hline & 26 & & 65 & 8 & $\nabla$ & 2.29 & 4.67 \\
\hline & 33 & & 57 & 11 & Minimum & 2.27 & 4.60 \\
\hline & 44 & & 41 & 15 & risk & 2.25 & 4.47 \\
\hline
\end{tabular}




\section{The shape of the frontier}

reduce apartments (down to 86 per cent). These investors would fall in the middle range of the efficient frontier. Finally, those highly risk-averse investors who prefer safety will increase their retail allocation (22-44 per cent) and hotel allocation (7-15 per cent) and reduce apartments (41-72 per cent) (percentages do not add up to 100 due to rounding).

Typically, the shape of the frontier also contributes to an understanding of the situation. Longer frontiers indicate that taking market risk is rewarding. As in the case of this study, risk assumption increases average semi-annual returns from 4.47 per cent to 4.95 per cent. Conversely, a short frontier would indicate that market risk is not worth assuming. A horizontal or flat frontier suggests a low marginal return from the assumption of additional risk, while steeper frontiers suggest higher incremental return with an increase in market risk. ${ }^{30}$

Finally, the optimiser was used to develop an efficient frontier (Figure 4) without hotels. It is instructive to note that this frontier was shorter and did not have the full spectrum of risk-reducing benefits associated with the inclusion of hotels in the portfolio mix. Furthermore, the lowest variance portfolio (bottom left) on the efficient frontier generated without hotels has a higher level of risk ( 2.35 per cent) for the same level of return when a frontier is generated with the inclusion of hotels. This further illustrates the risk-reduction properties of hotel real estate by including it in a multi-property real estate portfolio.

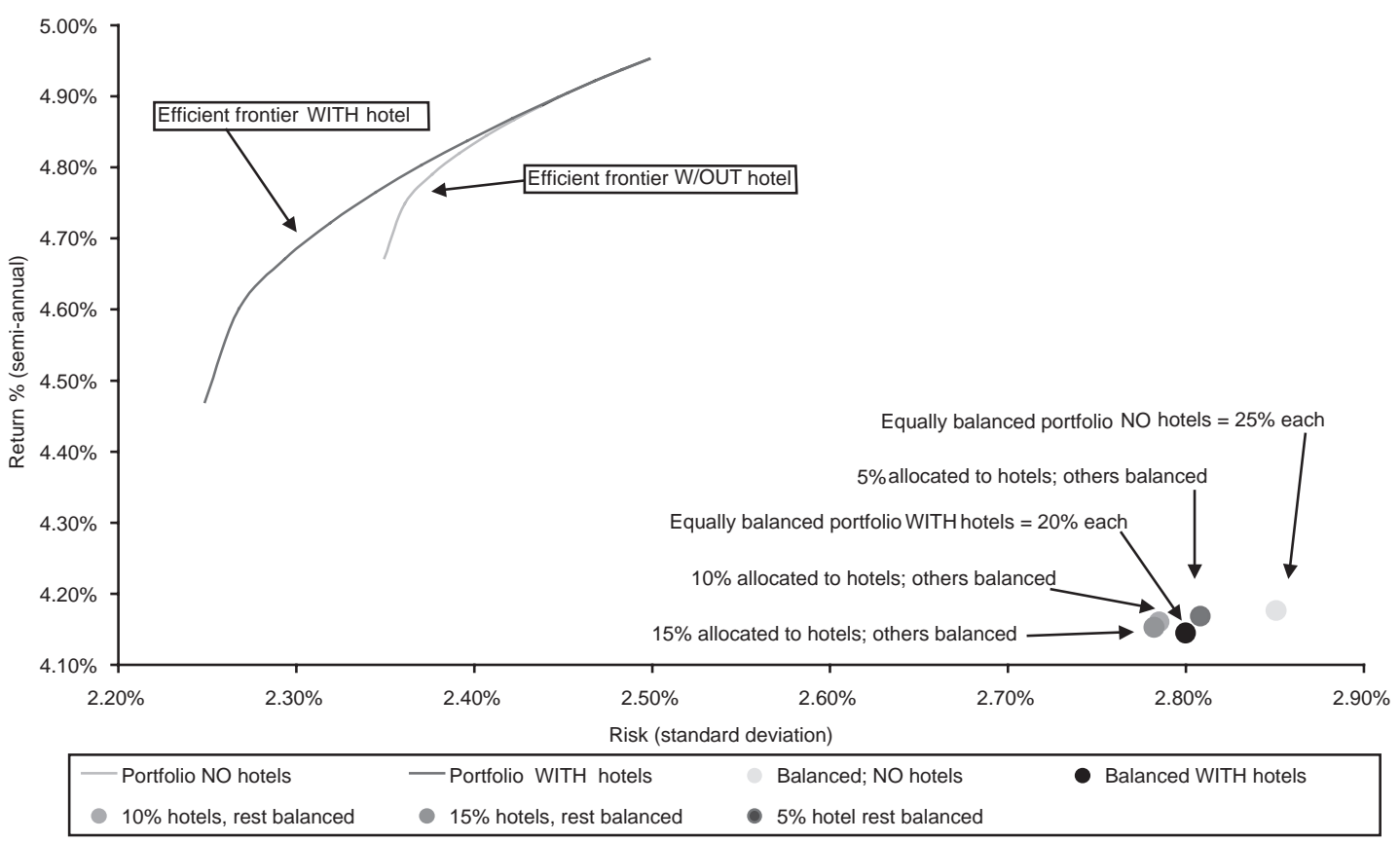

Figure 5: Performance statistics of simulated property portfolios 
Table 4: Simulated risk-return profile of multi-property real estate portfolio (1982-2001) (semiannual figures)

\begin{tabular}{llll}
\hline Portfolio alternatives & Risk \% & Return \% & Sharpe \\
\hline Equally balanced no hotel & 2.85 & 4.18 & 0.18 \\
Equally balanced with hotel & 2.80 & 4.14 & 0.17 \\
15\% allocation to hotel, rest equally balanced & 2.78 & 4.15 & 0.18 \\
$10 \%$ allocation to hotel, rest equally balanced & 2.79 & 4.16 & 0.18 \\
$5 \%$ allocation to hotel, rest equally balanced & 2.81 & 4.17 & 0.18 \\
\hline
\end{tabular}

\section{Developing simulated (illustrative) portfolios with and without hotels}

Figure 5 and Table 4 are the result of a combination of illustrative portfolios built deliberately to use as examples. In addition to the efficient frontiers and the risk return of the portfolios with and without hotels, the graph shows the result of building portfolios with an array of allocations to hotels (all other subsectors balanced) ranging from 5 to 20 per cent. The result of this simulation shows that (depending on the strategy of the investor) it would be beneficial for the investment manager to allocate a portion of the assets in a portfolio to the hotel subsector. By allocating a portion of the funds to hotels, the returns are reduced marginally but the risk is also reduced. It is interesting to note that the Sharpe ratios are virtually identical (except in the case of an equally balanced portfolio with hotels).

\section{IMPLICATION FOR PORTFOLIO MANAGEMENT}

The results of this study were based on the analysis of ex-post performance data. In essence, the results of the analysis indicated how portfolios would have performed given allocation of the weightings suggested at the beginning of the period. This, of course, is a weakness of this and most similar studies of this type, based on historical data. There is also the question of which data are more credible - historical data (fact) from which patterns of behaviour

\section{Expectations, forecasts or intuition} can be analysed, or future data (forecasts/expectations). In practice, the investor must make decisions based on expectations, forecasts or intuition, but an evaluation of the ex-post results presents valuable lessons for portfolio managers.

The ex-post results over a 20 -year period show the diversification benefits of hotels in a multi-property portfolio. These benefits include risk reduction and virtually equal risk-adjusted returns when hotels are included in a multi-property portfolio. While it is not prudent naively to extend past performance to predict future performance, these results make a strong argument for the inclusion of hotels when portfolio managers select the forecasting inputs (return, risk and correlations) to derive an ex-ante efficient frontier.

At an elementary level, portfolio managers can use the results of this research to compare the returns of their current real estate portfolio to the efficient frontier generated by this study, at any 


\section{Investor objectives}

\section{Investor objectives and market dynamics}

given level of risk. While the comparison is to past performance, it provides them with an incentive to explore the role of hotels in a multi-property portfolio. If their current portfolio is without hotels, they may be spurred to ask the question: given the low correlations of hotels to other real estate, to what extent will their inclusion in an investment portfolio reduce risk and improve returns?

Portfolio managers who use a disciplined approach to creating portfolios will start with an identification of investor objectives, which may include portfolio size, return requirements, risk tolerance, liquidity requirements and portfolio time horizon. Once the objectives are identified, the dynamics of the real estate market and of the individual property sectors are analysed. An understanding of investor objectives and market dynamics assists the manager in selecting the ex-ante inputs for the optimisation process. While historical performance provides the quantitative inputs, portfolio managers make their input decisions based on 'qualitative' and 'judgmental' factors. An understanding of the unique events and their impact on the specific property sectors will assist them in their decision-making process. This was extensively discussed for the hotel sector in this study. The results of the study will assist managers in ultimately selecting a target portfolio, which when compared to their current portfolio may result in repositioning the portfolio by implementing buy, hold or sell decisions.

\section{CONCLUSION}

The purpose of diversifying a real estate investment portfolio is to reduce or eliminate unsystematic risk. This is the risk which results from events which have a unique effect on a particular property sector. Because of these events, the returns of the different property sectors do not move in tandem. The results summarised in this study showed evidence of this cyclical industry behaviour over the long term, from 1982 to 2001. The periodic cycles included periods of growth, decline, stagnation and recovery. The individual risks and returns for each of the property sectors were different during this period, with the apartment subsector recording the highest returns and the hotel subsector the most volatile. From a portfolio management perspective the correlation of these returns has significant implications for the performance of the overall portfolio. By constructing an efficient frontier using ex-post data, the study demonstrated the diversification benefits derived by including hotels in a multi-property real estate portfolio.

\section{References and Notes}

1. Gibson, R. C. (2000) Asset Allocation: Balancing Financial Risk, 3rd edn, McGraw-Hill, New York.

2. Firstenberg, P. M., Ross, S. A. and Zisler, R. C. (1988) 'Real estate: The whole story', Journal of Portfolio Management, Spring, pp. 22-34.

3. Ibid. 
4. Wilson, S. H. (2000) 'Modern portfolio theory applied to real estate', in Wilson, S. H. (ed.) Modern Real Estate Portfolio Management, Frank Fabozzi and Associates, New Hope, PA, pp. 209-217.

5. Miles, M. E. and McCue, T. E. (1982) 'Historic returns and institutional real estate portfolios', AREUEA Journal, Vol. 10, No. 2, pp. 184-198.

6. Webb, J. R. (1984) 'Real estate investment acquisition rules for life insurance companies and pension funds: A survey', AREUEA Journal, Vol. 12, No. 4, pp. 495-520.

7. Ibbotson, R. G. and Siegel, L. B. (1984) 'Real estate returns: A comparison with other investments', AREUEA Journal, Vol. 12, pp. 219-241.

8. Hartzell, D. J. (1986) 'Real estate in the portfolio', in Fabozzi, F. J. (ed.) Institutional Investor: Focus on Investment Management, Ballinger, Cambridge, MA.

9. Hartzell, D. J., Hekman, J. S. and Miles, M. E. (1986) 'Diversification categories in investment real estate', AREUEA Journal, Vol. 14, No. 2, pp. 230-254.

10. Grissom, T. V., Kuhle, J. L. and Walther, C. H. (1987) 'Diversification works in real estate, too', Journal of Portfolio Management, Vol. 13, No. 2, pp. 66-71.

11. Myer, F. C. N. and Webb, J. R. (1991) 'Estimating allocations for mixed-asset portfolios using the bootstrap technique', paper presented at the American Real Estate Society meeting, Sarasota, Florida, April.

12. Mueller, G. R. and Laposa, S. P. (1995) 'Property type diversification in real estate portfolios: A size and return perspective', Journal of Real Estate Portfolio Management, Vol. 1, No. 1, pp. 39-50.

13. Firstenberg et al., ref. 2 above.

14. deRoos, J. A. and Corgel, J. B. (1996) 'Measuring lodging property performance', Cornell Hotel and Restaurant Administration Quarterly, Vol. 37, No. 4, pp. 20-27.

15. Corgel, J. B. and deRoos, J. A. (1997) 'Hotel investments in the portfolio: Are they part of the core?', Real Estate Finance, Vol. 14, No. 2, pp. 29-37.

16. Jointly created by the American Hotel and Lodging Association and Cornell University's School of Hotel Administration, LPI measures quarterly lodging property performance on an unleveraged return basis. The index currently represents about 2 per cent of the investment-grade hotels in the USA.

17. Quan, D. C., Li, J. and Sehgal, A. (2002) 'The performance of lodging properties in an investment portfolio', Cornell Hotel and Restaurant Administration Quarterly, Vol. 43, No. 6, pp. 81-89.

18. Viezer, T. W. (2000) 'Evaluating "within real estate" diversification strategies', Journal of Real Estate Portfolio Management, Vol. 6, No. 1, pp. 75-95.

19. Quan et al., ref. 17 above.

20. Ziering, B. A. and Stoesser, J. W. (1997) 'Development and implementation of an integrated portfolio management paradigm', Real Estate Finance, Vol. 14, No. 1, pp. 2135 .

21. Includes appreciation (or depreciation), realised capital gain (or loss) and income. It is computed by adding the income and capital appreciation return on a quarterly basis. NCREIF (2003) www. NCREIF.com.

22. www.NCREIF.com.

23. It is relevant to note that during the initial years of the 20 -year period the sample of data corresponding to the hotel subsector was fairly small ( 1 per cent) by number of properties, since the subsector was incorporated into the main databank only a few years earlier, during the early 1980 s.

24. Byrne, P. and Lee, S. L. (1994) 'Computing Markowitz efficient frontiers using a spreadsheet optimizer - Part 1', Journal of Property Finance, Vol. 5, No. 1, pp. 58-66; Byrne, P. and Lee, S. L. (1994) 'Computing Markowitz efficient frontiers using a spreadsheet optimiser - Part 2', Journal of Property Finance, Vol. 5, No. 4, pp. 19-31.

25. Singh, A. J. (1999) 'A 20th century history and Delphi study to predict changes in the lodging industry structure, performance and capital sources', doctoral dissertation, Michigan State University, Dissertation Abstracts International.

26. Ibid.

27. Sharpe ratio formula used: $\frac{r_{p}-r_{f}}{\sigma_{p}} \Rightarrow \frac{\text { Rate of return }- \text { Risk-free rate }}{\text { Standard deviation (volatility) }}$ 
28. Byrne, P. and Lee, S. L. (1995) 'Is there place for property in a multi-asset portfolio?', Journal of Property Finance, Vol. 6, No. 3, pp. 60-83.

29. The underlying data for the inputs were summarised in Tables 1 and 2.

30. Wilson, ref. 4 above. 